\title{
An Investigation on Exhaustion of SAP ERP Users: Influence of Pace of Change and Technostress
}

\author{
Prashanta Kumar Roy ${ }^{1}$, Imran Mahmud ${ }^{1,}$, Nusrat Jahan ${ }^{1}$ and Farzana Sadia ${ }^{1}$ \\ ${ }^{1}$ Department of Software Engineering, Daffodil International University, Bangladesh \\ prashanta.swe@gmail.com, imranmahmud@daffodilvarsity.edu.bd, (nusrat.swell sadia.swe)@diu.edu.bd \\ *Correspondence: imranmahmud@daffodilvarsity.edu.bd
}

Received: $5^{\text {th }}$ August 2017; Accepted: 15 ${ }^{\text {th }}$ September 2017; Published: $1^{\text {st }}$ October 2017

\begin{abstract}
Despite recent growing research interest on ERP research, the understanding on ERP induced exhaustion is still limited. This study examines how the pace of change of ERP functionalities and interface causes exhaustion in workplace. For this purpose, we conducted an investigation on 128 ERP users from two different organizations in Bangladesh. We extended theory of technostress by integrating pace of change of ERP system. Result suggests that pace of change on ERP system significantly affect work-overload, work-life conflict and role ambiguity on ERP users. Result also shows that work-overload and role ambiguity are strong predictors for ERP induced exhaustion.
\end{abstract}

Keywords: Technostress; SAP; ERP; Pace of Change

\section{Introduction}

Currently, managers from industries need to make swift planning and proficient judgment in order to sustain in a very competitive market. Since the last two decades, Enterprise Resource Planning Software Systems (ERPs) became a standard and archetypical technology to support stakeholders' decision practice within the industry.

The primary benefit of ERP systems relates to the integration of data and processes and improved business efficiency [1]. As a result of the potential benefits reaped by ERP systems, they have been adopted by the majority of enterprises globally. The world "Simple" does not go along with ERP system [2]. Inflexibility of ERP systems causes frustration to the users which encourage managers to hire more programmers and sometimes any changes in the process also create problem on change the functionality of ERP system.

Prior research suggested, general technologies [3], email [4], mobile phones [5] cause stress among employees at workplace. Research also suggested that ERP systems are complex because of poor interface usability [6][7][8]. By noting that, we believe that complex systems like ERP can also cause stress just like other information and communication technologies at workplace.

In this paper, we aim to provide a more detailed context of technology stress related factors rooted in theory of technostress of [3]. The key objective of this study is to test the impact of pace of change on techno-induced stressors like role ambiguity; work home conflict and work overload which leads to exhaustion at workplace. In doing so, the research question of our study is

$R Q$. Is there any influence of pace of change of ERP system cause technostress on users?

\section{Literature Review and Model Development}

Ref [9] explained stress as a condition of user where the individual's capability and work place demands do not match. Researcher also mentioned that IT integrated systems are tightly controlled and those affect the job design and overall work structure of users. Ref [3] updated the previous research models of [9] and [10]. Their research explained that features/functions of technology cause 
individuals to perceive stressors, which will make individuals to respond to these stressors psychologically.

Ref[11]investigated the unique attributes of office-home smartphone (OHS) use, such as work overload, productivity and flexibility and their impacts on work-to-life conflict and other work-related outcomes. Their research demonstrated that an increased work overload due to OHS use results in greater work-to-life conflict thus creating job stress and user resistance to OHS. Their study also reveals that the productivity gained due to OHS use can decrease work overload.

Some researchers conducted a user survey amongst 661 working professionals with the aim to build and test a model of technostress [3]. They made use of the person-environment fit model as a theoretical lens for their research. Evaluation of their proposed model advocates that some technology characteristic such as intrusiveness and dynamism i.e. pace of change are directly related to stressors e. g. role ambiguity, work overload, work-home conflict and so forth.

Based on the research of [3] we chose three stressors that can cause exhaustion or depression: work-overload, work-home conflict, role ambiguity. Ref.[12] argued that ERP systems are very exigent and radically changes the business process. ERP system related changes make users work environment indistinct and unsteady. Thus our hypotheses are

H1: Pace of change positively influence role ambiguity of users

H2: Pace of change positively influence work home conflict of users

H3: Pace of change positively influence work overload of users

In manufacturing industries using ERP is a secondary job in some cases. As a result, role ambiguity occurs when the perception of lacking clear about whether users should deal with ERP-problems or work activities. Again, when ERP systems creates tension over learning new features and lighten work home boundaries then work home conflict occurs. Similarly, ERP system creates demand on quick report generation and decision making but users might feel pressure about time and accurate data input. Thus we formulated the hypotheses as follows

H4: ERP induced role ambiguity positively influence exhaustion of users.

H5: ERP induced work home conflict positively influence exhaustion of users.

H6: ERP induced work overload positively influence exhaustion of users.

As a result, our proposed research models are shown in Figure 1 below.

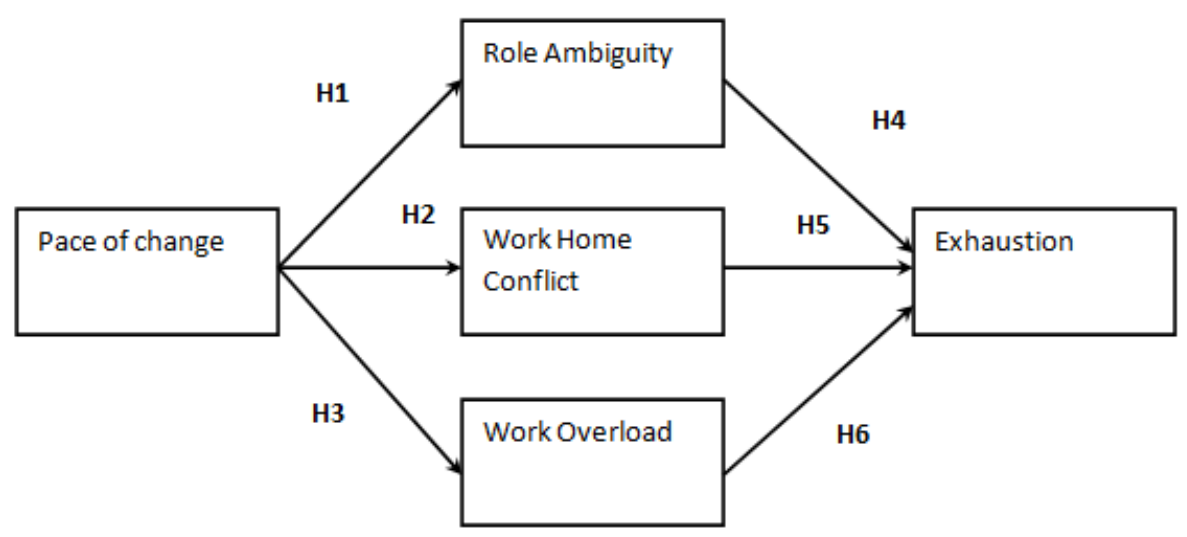

Figure 1.Research Model.

\section{Research Methodology}

\subsection{Data Collection Method}

A total of 300 questionnaires were distributed among the ERP users of two different manufacturing organizations in Dhaka, Bangladesh. 128 questionnaires in total were returned with $42.6 \%$ response rate. To make the research model significant including effect size 95 our required 
sample size was 119. Between two sections of questionnaire the first elicited the demographic data; and the second focused on items to measure the constructs of our research model.

\subsection{Measurement Items}

All of the measurement items were measured from published literature. To capture work-overload, work-life conflict, role ambiguity and exhaustion were adapted from [3]. The measure items for pace of change were adopted from the research of [12]. Likert scale ranges from $1=$ strongly disagree to $5=$ strongly agree presented with items to measure the theoretical concepts.

Table 1. Measurement Items

\begin{tabular}{|c|c|c|}
\hline \multicolumn{3}{|c|}{ Pace of change } \\
\hline PC1 & I feel that there are frequent changes in the features of ERP. & \multirow[t]{2}{*}{ [12] } \\
\hline PC2 & I feel that characteristics of ERP change frequently & \\
\hline \multicolumn{3}{|c|}{ Work Home Conflict } \\
\hline WHC1 & Using ERP. blurs boundaries between my job and my home life. & \multirow[t]{3}{*}{ [3] } \\
\hline WHC2 & $\begin{array}{l}\text { Using ERP. for work-related responsibilities creates conflicts } \\
\text { with my home responsibilities. }\end{array}$ & \\
\hline WHC3 & $\begin{array}{l}\text { I do not get everything done at home because I find myself } \\
\text { completing job-related work due to ERP. }\end{array}$ & \\
\hline \multicolumn{3}{|c|}{ Work Overload } \\
\hline WO1 & $\begin{array}{c}\text { ERP. create many more requests, problems, or complaints in my } \\
\text { job than I would otherwise experience. }\end{array}$ & \multirow[t]{3}{*}{ [3] } \\
\hline WO2 & I feel busy or rushed due to ERP. & \\
\hline WO3 & I feel pressured due to ERP. & \\
\hline \multicolumn{3}{|c|}{ Role Ambiguity } \\
\hline RA1 & $\begin{array}{l}\text { I am unsure whether I have to deal with ERP problems or with } \\
\text { my work activities. }\end{array}$ & \multirow[t]{4}{*}{ [3] } \\
\hline RA2 & $\begin{array}{l}\text { I am unsure what to prioritize: dealing with ERP problems or } \\
\text { my work activities. }\end{array}$ & \\
\hline RA3 & $\begin{array}{c}\text { I can NOT allocate time properly for my work activities because } \\
\text { my time spent on ERP.s-activities varies. }\end{array}$ & \\
\hline RA4 & $\begin{array}{l}\text { Time spent resolving ERP problems takes time away from } \\
\text { fulfilling my work responsibilities }\end{array}$ & \\
\hline \multicolumn{3}{|c|}{ Exhaustion } \\
\hline EX1 & I feel drained from activities that require me to use ERP. & \multirow[t]{4}{*}{ [3] } \\
\hline EX2 & I feel tired from my ERP activities. & \\
\hline EX3 & Working all day with ERP is a strain for me. & \\
\hline EX4 & I feel burned out from my ERP activities. & \\
\hline
\end{tabular}

\subsection{Sample Profile}

The demographic respondents tabulated in Table 2 which were derived from descriptive analysis. The majority of the age group (49.2\%) was in the category of 25-29 years old. Most of the respondents were Male $(79.6 \%)$ than the females $(20.3 \%) .67 .1 \%$ of total respondents use ERP system more than 5 hours. 
Table 2. Demographic Info

\begin{tabular}{|c|c|c|}
\hline PercentageFrequency & & \\
\hline \multicolumn{3}{|l|}{ Gender } \\
\hline Male & 102 & 79.6 \\
\hline Female & 26 & 20.3 \\
\hline \multicolumn{3}{|l|}{ Age } \\
\hline $25-29$ & 55 & 42.9 \\
\hline $30-35$ & 38 & 29.6 \\
\hline More than 35 & 35 & 27.3 \\
\hline \multicolumn{3}{|l|}{ Use of ERP } \\
\hline $1-5 \mathrm{hrs}$ & 42 & 32.8 \\
\hline 5 to $10 \mathrm{hrs}$ & 86 & 67.1 \\
\hline
\end{tabular}

\subsection{Data Analysis Techniques}

Smart PLS version 2.0, a variance based Structural Equation Modelling (SEM) was used to analyze the hypotheses. The reasons of using this technique are as follows:

(a) PLS is an appropriate technique to analyze m method for testing a multivariate, multi-path model[13].

(b) PLS places a minimal restriction on the sample size [14]

The two-step analytical procedure suggested by [15] was adopted to analyze data whereby the measurement model was evaluated first and then followed by the structural model. Also, following the suggestion of [14], the bootstrapping method (500 resample) was done to determine the significant level of loadings, weights, and path coefficients.

\section{Result}

\subsection{Measurement Model}

Convergent validity is the degree which indicate specific construct that should converge or share a high proportion of variance. According to [16], factor loadings and average variance extracted (AVE) more than 0.5 and composite reliability (CR) of 0.7 or above is seemed to be acceptable. According to Table 3, AVE of the constructs is above 0.5 and the composite reliability values are more than 0.7 . So, we can conclude that convergent validity has been established.

Next, we have assessed the discriminate validity which extent a construct which is truly distinct from other [16]. This can be established by the low correlations between all measures of interest and the measures of other constructs. To address discriminate validity, the square root of the AVE is compared against the correlations of other constructs, when the AVE is greater than its correlations with all other constructs then discriminate validity has been established [17][18] (refer Table 4).

Table 3. Composite reliability and AVE

\begin{tabular}{|c|c|c|}
\hline & Composite Reliability & Average Variance Extracted (AVE) \\
\hline EX & 0.909 & 0.715 \\
\hline PC & 0.913 & 0.839 \\
\hline RA & 0.904 & 0.702 \\
\hline WHC & 0.829 & 0.618 \\
\hline WO & 0.850 & 0.656 \\
\hline
\end{tabular}


Table 4. Discriminant Validity

\begin{tabular}{|l|l|l|l|l|l|}
\hline & EX & PC & RA & WHC & WO \\
\hline EX & $\mathbf{0 . 8 4 6}$ & & & & \\
\hline PC & 0.266 & $\mathbf{0 . 9 1 6}$ & & & \\
\hline RA & 0.735 & 0.254 & $\mathbf{0 . 8 3 8}$ & & \\
\hline WHC & 0.422 & 0.499 & 0.455 & $\mathbf{0 . 7 8 6}$ & \\
\hline WO & 0.529 & 0.276 & 0.530 & 0.623 & $\mathbf{0 . 8 1 0}$ \\
\hline
\end{tabular}

Note: Diagonal represents the square root of Average Variance Extracted (AVE) while the other entries represent squared correlations

\subsection{Structural Model}

The structural model represents the relationship between constructs or latent variables that were hypothesized in the research model. Table 5 and figure 2, shows the results of the structural model from the PLS output and out of six, five of our hypotheses are strongly significant. Pace of change (PC) has significant influence on $\operatorname{RA}(\beta=0.254, \mathrm{p}<0.01), \mathrm{WHC}(\beta=0.499, \mathrm{p}<0.01)$ and $\mathrm{WO}(\beta=$ $0.276, \mathrm{p}<0.01)$. Further, $\operatorname{RA}(\beta=0.628, \mathrm{p}<0.01)$ and $\mathrm{WO}(\beta=0.180, \mathrm{p}<0.01)$ are found strong predictor of EX. But our final hypothesis H6 is not significant which means WHC has no significant relation with EX.

Table 5. Hypothesis Test Result

\begin{tabular}{|c|c|c|c|c|c|}
\hline & Relationship & $\begin{array}{c}\text { Path } \\
\text { co-efficient }\end{array}$ & T Statistics & P Values & Remark \\
\hline H1 & PC - RA & 0.254 & 3.036 & 0.003 & Supported \\
\hline H2 & PC - WHC & 0.499 & 7.309 & 0.000 & Supported \\
\hline H3 & PC - WO & 0.276 & 3.036 & 0.003 & Supported \\
\hline H4 & RA -> EX & 0.628 & 9.702 & 0.000 & Supported \\
\hline H5 & WHC -> EX & 0.024 & 0.293 & 0.769 & Not Supported \\
\hline H6 & WO - EX & 0.180 & 2.389 & 0.017 & Supported \\
\hline
\end{tabular}

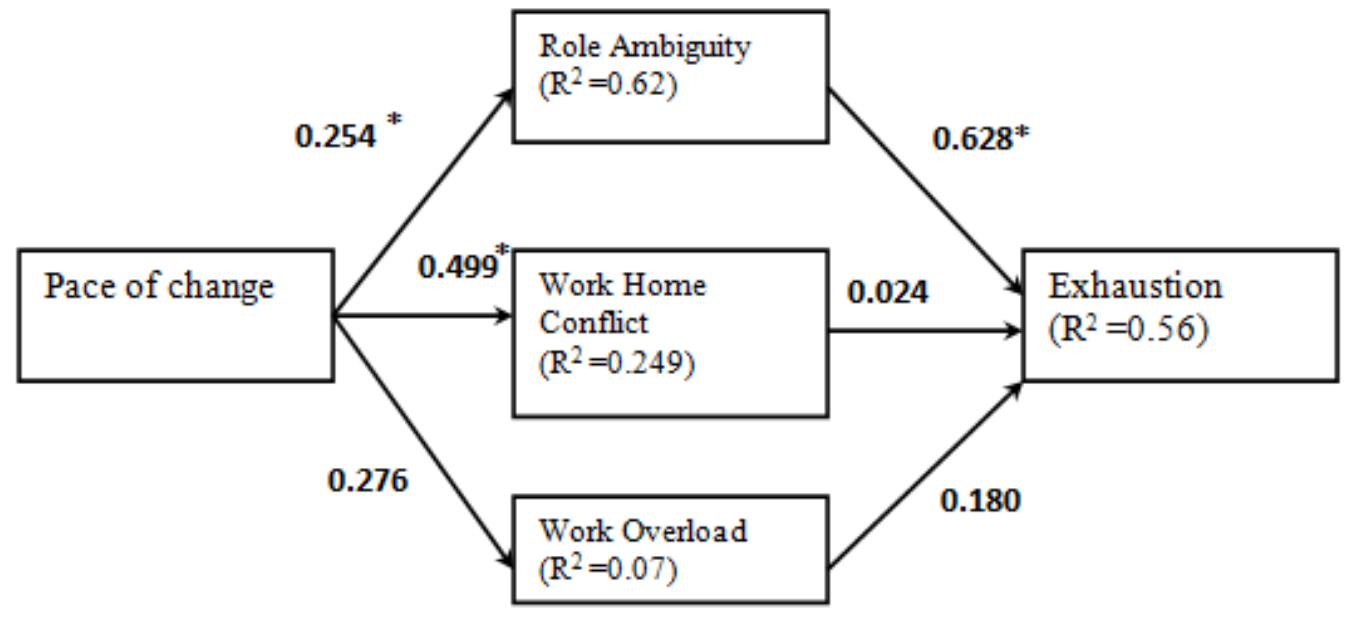

Figure 2. Research Model with result 


\section{Discussion and Implications}

This research aims to identify whether pace of change for ERP system triggers techno-induces stressors which leads to exhaustion. Our result reveals that pace of change strongly influences stressors like role ambiguity, work home conflict and work overload. Analysis result shows that pace of change explains $62 \%, 24 \%$ and $7 \%$ variance role ambiguity, work home conflict and work overload consequently. Our hypotheses test results are consistent with the research of [12][19]. According to our data, role ambiguity, work overload and work-home conflict explains $56 \%$ variance on exhaustion related ERP system. These findings are aligned with the research of [3]. The relationship between work home conflict and exhaustion was positive but not significant. We assume that, most of ERP used in Bangladesh are offline system and connected through intranet. As a result, users can't work from home which put less pressure on them.

The research enriches the body of knowledge related ERP system and technostress. Theoretically, it extends the original theory of technostress by including pace of change.

\section{References}

[1] Huang, S. Y., Huang, S., Wu, T., \& Lin, W. (2009). Process efficiency of the enterprise resource planning adoption. Industrial Management \& Data Systems, 109(8), 1085-1100

[2] Tenhiälä, A., \&Helkiö, P. (2015). Performance effects of using an ERP system for manufacturing planning and control under dynamic market requirements. Journal of Operations Management, 36, 147-164.

[3] Ayyagari, R., Grover, V., \& Purvis, R. (2011). Technostress: technological antecedents and implications. MIS quarterly, 35(4), 831-858.

[4] Barley, S. R., Meyerson, D. E., \&Grodal, S. (2011). E-mail as a source and symbol of stress. Organization Science, 22(4), 887-906.

[5] Lee, Y. K., Chang, C. T., Lin, Y., \& Cheng, Z. H. (2014). The dark side of smartphone usage: Psychological traits, compulsive behavior and technostress. Computers in Human Behavior, 31, 373-383.

[6] Wong, W. P., Veneziano, V., \& Mahmud, I. (2015). Usability of Enterprise Resource Planning software systems an evaluative analysis of the use of SAP in the textile industry in Bangladesh. Information Development, 0266666915585364 .

[7] Veneziano, V., Mahmud, I., Khatun, A., \& Peng, W. W. (2014, December). Usability analysis of ERP software: Education and experience of users' as moderators. In Software, Knowledge, Information Management and Applications (SKIMA), 2014 8th International Conference on (pp. 1-7). IEEE.

[8] Scholtz, B., Mahmud, I., \&Ramayah, T. (2016). Does Usability Matter? An Analysis of the Impact of Usability on Technology Acceptance in ERP Settings. Interdisciplinary Journal of Information, Knowledge, and Management, 11.

[9] Ragu-Nathan, T. S., Tarafdar, M., Ragu-Nathan, B. S., \&Tu, Q. (2008). The consequences of technostress for end users in organizations: Conceptual development and empirical validation. Information Systems Research, 19(4), 417-433.

[10] Tarafdar, M., Tu, Q., \& Ragu-Nathan, T. S. (2010). Impact of technostress on end-user satisfaction and performance. Journal of Management Information Systems, 27(3), 303-334.

[11] Yun, H., Kettinger, W. J., \& Lee, C. C. (2012). A new open door: the smartphone's impact on work-to-life conflict, stress, and resistance. International Journal of Electronic Commerce, 16(4), 121-152.

[12] Maier, C., Laumer, S., \&Weinert, C. (2015). Enterprise resource planning systems induced stress: a comparative empirical analysis with young and elderly SAP users. In Wirtschaftsinformatik (pp. 1391-1406).

[13] Hair, J, F., Sarstedt, M., Hopkins, L., \& G. Kuppelwieser, V. 2014. Partial least squares structural equation modeling (PLS-SEM) An emerging tool in business research. European Business Review, 26(2), 106-121. 
[14] Chin, W. W. 1998. The partial least squares approach to structural equation modeling. Modern methods for business research, 295(2), 295-336.

[15] Anderson, J. C., \&Gerbing, D. W. 1988. Structural equation modeling in practice: A review and recommended two-step approach. Psychological bulletin, 103(3), 411.

[16] Hair, J. F., Ringle, C. M., \&Sarstedt, M. 2011. PLS-SEM: Indeed a silver bullet. Journal of Marketing theory and Practice, 19(2), 139-152.

[17] Fornell, C., \&Larcker, D. F. 1981. Structural equation models with unobservable variables and measurement error: Algebra and statistics. Journal of marketing research, 382-388.

[18] Alzahrani, A. I., Mahmud, I., Ramayah, T., Alfarraj, O., \&Alalwan, N. (2017). Extending the theory of planned behavior (TPB) to explain online game playing among Malaysian undergraduate students. Telematics and Informatics, 34(4), 239-251.

[19] Mahmud, I., Ramayah, T., \&Kurnia, S. (2017). TO USE OR NOT TO USE: MODELLING END USER GRUMBLING AS USER RESISTANCE IN PRE-IMPLEMENTATION STAGE OF ENTERPRISE RESOURCE PLANNING SYSTEM. Information Systems., 69, 164-179

(C) 2017 by the author(s). Published by Annals of Emerging Technologies in Computing (AETiC), under the terms and conditions of the Creative Commons Attribution (CC BY) license which can be accessed at http://creativecommons.org/licenses/by/4.0/. 